\title{
Teaching Yoga to Seniors: Essential Considerations to Enhance Safety and Reduce Risk in a Uniquely Vulnerable Age Group
}

\author{
Carol Krucoff, E-RYT, Kimberly Carson, MPH, E-RYT, ${ }^{2}$ Matthew Peterson, PhD, ${ }^{3}$ \\ Kathy Shipp, PT, MHS, PhD, and Mitchell Krucoff, MD, FACC, FAHA ${ }^{5}$
}

\begin{abstract}
Background: Seniors age 65 and older represent the fastest-growing sector of the population and, like many Americans, are increasingly drawn to yoga. This presents both an extraordinary opportunity and a serious challenge for yoga instructors who must be both a resource and guardians of safety for this uniquely vulnerable group. A typical class of seniors is likely to represent the most diverse mix of abilities of any age group. While some may be exceedingly healthy, most fit the profile of the average older adult in America, $80 \%$ of whom have at least one chronic health condition and $50 \%$ of whom have at least two.

Objectives: This article discusses the Therapeutic Yoga for Seniors program, offered since 2007 at Duke Integrative Medicine to fill a critical need to help yoga instructors work safely and effectively with the increasing number of older adults coming to yoga classes, and explores three areas that pose the greatest risk of compromise to older adult students: sedentary lifestyle, cardiovascular disease, and osteoporosis. To provide a skillful framework for teaching yoga to seniors, we have developed specific Principles of Practice that integrate the knowledge gained from Western medicine with yogic teachings.
\end{abstract}

\section{Introduction}

W E ARE IN THE MIDST of one of the greatest sociological shifts in history: Global aging. While the entire world is graying-developed countries are leading the way. ${ }^{1}$ In the United States, seniors age 65 and older represent the fastestgrowing sector of the population. ${ }^{2}$ This group is expected to more than double to over 80 million by the year 2050-with nearly one quarter 85 and older. ${ }^{3}$

Like many Americans, older adults are increasingly drawn to yoga. This presents both an extraordinary opportunity and a serious challenge for yoga instructors, who must be both a resource and guardians of safety for this uniquely vulnerable group. A typical class of seniors, which we define as "over age 65 ," is likely to represent the most diverse mix of abilities of any age group. Today's seniors may be extremely healthy and fit-able to run marathons, do headstands, and compete in masters athletic events. However, much more common are seniors who fit the profile of an "average" older adult in America, $80 \%$ of whom have at least one chronic health condition ${ }^{4}$ and $50 \%$ of whom have at least two. ${ }^{5}$ Most seniors face a broad array of health challenges, ranging from arthritis and incontinence to hip and knee replacement, heart disease, and cancer. Consider the health statistics for people over $65^{6}$ :

- $52 \%$ of men and $54 \%$ of women have high blood pressure.

- $43 \%$ of men and $54 \%$ of women have arthritis.

- $37 \%$ of men and $26 \%$ of women have heart disease.

- $24 \%$ of men and $19 \%$ of women have cancer.

- $19 \%$ of men and $17 \%$ of women have diabetes.

- $11 \%$ of men and $10 \%$ of women have chronic bronchitis or emphysema.

- $10 \%$ of men and $8 \%$ of women have had a stroke.

- $11 \%$ of men and $17 \%$ of women have clinically relevant depressive symptoms.

More than half of all adults over age 65 have a disability and more than a third have severe disability. ${ }^{7}$ More than $87 \%$ of seniors take at least one prescription drug and nearly

\footnotetext{
${ }^{1}$ Duke Integrative Medicine, Duke University, Durham, NC.

${ }^{2}$ Oregon Health \& Science University, Portland, OR.

${ }^{3}$ Geriatrics Department, Duke University, Durham, NC.

${ }^{4}$ Physical Therapy Department, Duke University, Durham, NC.

${ }^{5}$ Department of Cardiology, Duke University, Durham, NC.
} 
$60 \%$ take three or more. ${ }^{8}$ The average 75 -year-old has three chronic conditions and uses five prescription drugs. ${ }^{9}$ Several classes of medications commonly taken by seniors-including antihypertensives, antianxiety drugs, and antidepressantsare associated with dizziness, in particular postural dizziness, so it is not surprising that prevalence rates for dizziness in the older adult population may be as high as $38 \%{ }^{10}$ This is of particular concern, since falls are the leading cause of injury deaths and the most common cause of injuries and hospital admissions for trauma in this age group. ${ }^{11}$

These sobering statistics present a tremendous opportunity for yoga teachers and yoga therapists to help senior students improve their strength and enhance their balance to reduce their risk of falls, add comfort and control to breathing, and contribute to vitality, mood and alertness. These data also highlight the potential for harm that could occur if yoga instructors do not create a safe environment and class structure geared appropriately to older adults.

Another vital fact is that an estimated $30 \%$ of postmenopausal women have osteoporosis, ${ }^{12}$ a disorder of impaired bone strength that results in skeletal fragility and increased fracture risk. One (1) of every 2 women over age 50 will have an osteoporosis-related fracture in their lifetime, with risk of fracture increasing with age. Each year an estimated 1.5 million people suffer an osteoporotic-related fracture, an event that often leads to a downward spiral in physical and mental health. In fact, $20 \%$ of seniors who suffer a hip fracture die within 1 year. ${ }^{13}$ Osteoporosis is considered a "silent disease," since people who have this condition are often unaware of the problem until they suffer a fracture. This means it is quite likely that older adult yoga students, particularly females, will have osteoporosis and be at risk of fracture, but not know this-and, of course, will not be able to inform their yoga instructor that they need modified programs.

In addition to being at greater risk for osteoporotic fracture, older adults are also at greater risk for numerous other potentially life-threatening ailments, including heart attack and stroke. Finally, seniors are also far more likely than younger groups to have health challenges that affect their participation in a yoga class-ranging from hearing and vision loss to tremors, dementia, and incontinence.

Like the reality society faces with an historical proportion of our population living to more advanced ages than ever before with a very broad range of functional capacities and needs, yoga teachers of older adults are-in many waysnavigating uncharted territory. The great sages who originated the yogic practices thousands of years ago had never encountered artificial joints, canisters of supplemental oxygen, or prosthetic heart valves in large numbers of people who have reached extremely advanced age. As recently as 1900 , the average life expectancy in the United States was 46.3 for men and 48.3 for women. In 2005 that number had jumped to 75.2 for men and 80.4 for women. ${ }^{14}$

Training yoga teachers who work with seniors-like all practice of healing arts-represents a blend of scientific knowledge and research, philosophy, and opinion based on direct experience. It is our belief that, in service of ahimsa and the imperative to "first do no harm," yoga teachers working with seniors should recognize the importance of adapting the practice to senior bodies, minds, and spirits.

\section{The Therapeutic Yoga for Seniors Program at Duke Integrative Medicine: \\ A Brief Background}

Western medical science offers a wealth of knowledge in the arena of aging and disease, but many yoga teachers have limited access to this valuable input. The Therapeutic Yoga for Seniors program was created to fill a critical need to help yoga instructors work safely and effectively with the increasing number of older adults coming to yoga classes and was launched in 2007 when Duke University Health System opened its integrative medicine facility. The goal is to combine the best of modern, evidence-based medicine with the ancient wisdom, experience, and tradition of yogic teachings. It has evolved from a 3-day workshop to its current format as an 8-day teacher training with a mentored practicum, held twice annually at Duke Integrative Medicine (www .dukeintegrativemedicine.org). The curriculum involves a balance of lectures, movement and meditation practices, small group work and discussions, and features presentations by a variety of Duke University faculty including physicians, exercise physiologists, physical therapists, and health psychologists. The program covers health conditions common to seniors, such as heart disease, pulmonary disease, arthritis, and osteoporosis, and also addresses special issues in teaching seniors including pain management, spirituality and aging, and end-of-life issues.

Creating a safe environment for older adult students is of paramount importance. Equally essential is ensuring that this imperative of safety does not translate into establishing a fearful or limiting tone, but rather invites the empowering recognition of yoga's highest teachings that our true nature is already whole. To this end, yoga teachers are encouraged to fully welcome older adult students as they are, rather than being attached to expectations of how things should be, including how a body should move. To provide a skillful framework for teaching yoga to seniors, specific Principles of Practice were developed, which integrate knowledge gained from Western medicine with yogic teachings (Table 1). At the heart of these Principles of Practice is the recognition that how yoga is taught to seniors is as important as what is taught. For example, the principle of honoring Feeling Over Form suggests a teaching style that focuses on inviting students to move with a specific intention of a posture, exploring their own sensations and letting how the pose feels guide their movements. This is in contrast to telling students specifically what their body should look like in a pose. Another principle, Emphasize Fluidity, is particularly important as the body tends to become rigid with age and the circulation is more sensitive to fluctuations during the respiratory inhale/exhale cycle.

While the training covers many of the medical concerns common to seniors, for the purposes of this article, we have chosen to focus on three that pose the greatest risk of compromise to senior students: sedentary lifestyle, cardiovascular disease, and osteoporosis.

\section{Effects of Aging and the Impact of Physical Activity}

Some physical decline is inevitable with aging. While healthy lifestyle habits-including activity such as yoga practice, proper nutrition and social contact-can help slow the aging process, the reality is that eventually flesh weakens and everyone born must die. In general, as humans grow 
Table 1. Carson-Krucoff Principles of Practice ${ }^{a}$

1. First, Do No Harm. Join with our physician colleagues in making this our primary intention.

2. Create a Safe Environment. Cultivate ahimsa (nonharming) by encouraging students to honor their own personal journey and explore their full potential, with compassion and integrity.

3. Encourage Yogic Balance. Sthira sukham asanam-A yoga pose is, by Patanjali's definition, stable and comfortable. Invite students to challenge themselves, but never strain.

4. Meet People Where They Are. Honor individual abilities and limitations by offering accessible and appropriate modifications that reflect the intention and function of traditional postures.

5. Emphasize Feeling Over Form. Let go of ideas of how a pose should look. Focus instead on how a pose feels. Teach students to discriminate between discomfort, which may be welcomed as an inherent part of the growth process, and pain, which is to be avoided.

6. Honor the Inner Teacher. Don't assume you know what's going on with someone, even if you've asked. Consider yourself a guide, helping students explore what works best for them.

7. Encourage Gratitude and Joy. Create an environment that celebrates what students can do.

8. Emphasize Fluidity. The Tao's teaching that "those who are soft and supple are disciples of life" is particularly important as the body becomes rigid with age. Minimize static "holdings."

9. Use Skillful Language. Encourage and invite rather than direct and demand.

10. Respect Our Scope of Practice. Recognize that what we do as yoga teachers is only part of the integrative health care landscape. Do only what we are trained to do and refer to other practitioners when necessary.

11. Be a Guardian of Safety. Get CPR/AED training and keep your certification current.

12. Teach People, Not Poses or Conditions. While acknowledging the inevitable changes inherent in life, it is essential to recognize the unchanging spirit at the heart of all beings.

${ }^{a}$ From Therapeutic Yoga for Seniors, Teacher Training Manual, (c 2008 Kimberly Carson and Carol Krucoff.

$\mathrm{CPR}$, cardiopulmonary resuscitation; AED, automated external defibrillator.

older, systems become slower to react and recover, the heart and blood vessels becomes stiffer, lung capacity decreases, the kidneys' filtering capacity is reduced, bones weaken, and muscle mass declines. Sleep disturbances become more common, and older adults often sleep less deeply, wake up more often throughout the night, and have more trouble falling asleep. ${ }^{15}$ Hearing is often compromised, with $35 \%$ of women and $48 \%$ of men over age 65 reporting trouble hearing. ${ }^{6}$

Despite the inevitable declines, a growing body of research suggests that the way in which older adults spend their final years-either frail in a nursing home, or vital and living independently-may be greatly influenced by their physical activity habits, throughout their lifetime and in their later years. "Current evidence clearly indicates that participation in a regular exercise program is an effective way to reduce and/or prevent a number of the functional declines associated with aging," according to the American College of Sports Medicine's (ACSM) statement on Exercise and the Older Adult. ${ }^{16}$ As mounting scientific evidence supports the myriad health benefits of regular physical activity, public health officials have launched campaigns to encourage people to become more active. The sad fact is that less than one quarter of all adults exercise regularly and "physical inactivity is second only to tobacco use as a cause of death in the United States, responsible for an estimated 400,000 deaths per year." 17 In 2008, the U.S. Department of Health and Human Services issued their first-ever Physical Activity Guidelines for Americans, which noted: Most health benefits occur with at least 150 minutes a week (the equivalent of five, 30-minute sessions) of moderate intensity physical activity, such as brisk walking. Additional benefits occur with more physical activity. ${ }^{18}$

A key feature of these new guidelines is a section devoted to older adults (defined as age 65 and older), who are not only the least physically active of any age group, but also generate the highest expenditures for medical care. The guidelines advise older adults to avoid inactivity, participate in regular aerobic activity, do muscle-strengthening activities, and do exercise that maintains or improves balance. $^{19}$

Flexibility exercises are recommended in a similar set of guidelines, jointly released by the American Heart Association and the American College of Sports Medicine in 2007. ${ }^{20}$ These guidelines recommended use of a Perceived Exertion scale to determine an appropriate level of exercise intensity. This 10-point scale defines "sitting" as " 0 " and "all-out effort" as " 10 " - with moderate-intensity activity in the " 5 " or " 6 " range (Table 2). Rather than gauge intensity by an external device such as a heart rate monitor, this Perceived Exertion scale invites each individual to determine how effortful something feels. Since people's abilities and fitness levels vary, the perception of "moderate intensity" effort will vary-with some reporting that climbing several flights of stairs is a moderate intensity activity, while others saying that moderate-intensity activity is getting up off the couch to answer the door.

While the yoga practice is clearly more than a "workout," it certainly fits into the public health mandate encouraging regular movement. In fact, many of the activities currently being promoted for older adults-such as balance training

Table 2. Perceived Exertion: 10-Point Effort Scale

\begin{tabular}{ll}
\hline 0 & Sitting-no movement \\
$1-2$ & Very light activity \\
$3-4$ & Light activity \\
$5-6$ & Moderate-intensity effort \\
$7-8$ & High-intensity effort \\
10 & All-out effort \\
\hline
\end{tabular}


and flexibility exercise-are integral parts of most yoga classes. And yoga teachers will likely recognize the Western "Perceived Exertion" scale as a subjective measure of intensity, quite similar to yogic teachings that advise practitioners to find their own comfortable and stable seat in each posture.

\section{Cardiovascular Disorders and Seniors}

Age is one of the most significant risk factors for all cardiovascular ailments. This includes coronary artery disease (CAD), which is the number one cause of death and disability for both men and women in the United States, ${ }^{21}$ as well as numerous other chronic and potentially lifethreatening cardiovascular conditions such as hypertension, congestive heart failure, arrhythmias, valvular disorders, and stroke. With advancing age, the elastic elements of the blood vessels are progressively replaced by more leathery, fibrous tissue. In addition, progressive deposition of cholesterol plaque-known as atherosclerosis, or hardening of the arteries-in the inner walls of the arteries can also compromise blood flow to vital organs such as the brain, kidneys, and the heart itself. Loss of elasticity in the heart muscle itself can lead to symptoms of heart failure. Wear and tear on the blood vessels over time can lead to aneurysms and clots, while wear and tear on the heart valves can lead to narrowing and leaking. The most catastrophic of clinical cardiovascular outcomes-death, stroke, heart attack, heart failure, blood vessel rupture, sudden loss of consciousness-all occur more frequently just by virtue of advancing age.

The risk for the most common form of heart disease, CAD, increases in midlife-beginning at age 45 for men and age 55 for women. The narrowing or blockage of arteries characteristic of CAD can lead to a variety of ailments including the following:

- Angina, which consists of pain, pressure, or burning symptoms in the neck, chest, or arm, often associated with exertion or stress

- Irregular heart rhythms, ranging from minor to lifethreatening

- Fast or slow heart rate

- Breathlessness, easy fatigability, dizziness, and loss of tolerance for exertion

- Congestive heart failure

- Heart attack, with irreversible heart muscle damage caused by sustained interruption in the blood supply to the heart.

Each year, about 1.2 million Americans will have a first or recurrent heart attack, and about 452,000 of them will dienearly three fourths of whom die in the emergency department or before reaching a hospital. ${ }^{22}$ Surprisingly, an estimated $50 \%$ of men and $64 \%$ of women who died suddenly of CAD had no previous symptoms of this disease. ${ }^{23}$ Like osteoporosis and hypertension, CAD can be a "silent disease," because there are often no symptoms until the disease reaches a critical point. It is highly recommended that anyone working with seniorsincluding yoga instructors-be certified in cardiopulmonary resuscitation, $\mathrm{CPR}$, a potentially lifesaving technique taught around the world by organizations such as the Red Cross and the American Heart Association. Today, most CPR classes also include instruction in using the automated external defibrillator (AED), a portable electronic device that automatically diagnoses potentially life-threatening cardiac arrhythmias. AEDs are now generally available in most public places-including community centers, airports, and schools-and it is also advisable for anyone teaching seniors to know the location of the nearest AED. Yoga studios might consider purchasing AEDs, which are as commercially available as fire extinguishers.

Aging is associated with loss of blood vessel elasticity, and seniors frequently have chronic hypertension, often treated with medicines that affect blood vessel tone and circulating blood volume. Loss of elastic resilience in the blood vessels with age also makes seniors more susceptible to both sudden elevation of blood pressure and to dizziness from low blood pressure related to sudden changes in posture, breath holding, and heavy lifting.

Yoga instructors who work with seniors do not need to become cardiologists, nor should they try to be. If a senior student becomes suddenly uncomfortable, dizzy, or ill with a sense of nausea, chest pain, or short windedness, calling 911 for professional assistance is the immediate next step. On the other hand, cardiovascular knowledge and awareness is a critical educational element for anyone working with seniors.

Another key dimension of cardiovascular awareness and yoga for seniors is in the mind-body-spirit milieu, which fits well in the most ancient yogic traditions and to which modern Western cardiology has begun to gain insight. ${ }^{24}$ Seniors, like all people with cardiovascular disorders, face immediate and penetrating questions of personal mortality. Personal styles and social forces that often affect seniors in Western civilization-social isolation, depression, loneliness, hostility-have all been shown to significantly affect both quality and length of life in people with heart disease. While specific mechanisms are still under study, a growing body of evidence suggests that certain brain-heart signals can be influenced by intangible factors that are typically part of the yoga practice, such as relaxation, mindfulness, prayerfulness, meditation, and group support. ${ }^{25}$

For yoga instructors working with older adults, these and related findings should shed light on the potential impact of wisdom-based yogic instruction for modern seniors. As the most vulnerable humans to both physiologic and spiritual "loss of heart" in Western society, seniors are perhaps the yoga students with both the most to lose and the most to gain from yoga practice.

To ensure the safety of senior yoga students as well as reduce the personal liability of the yoga instructor/therapist, it is highly recommended that a very short, simple clinical history be documented before joining classes. Is there any history of heart disease, high blood pressure, or stroke? Has any surgery or procedure ever been performed on any blood vessel, heart valve, or pacemaker? Are any prescription medicines being taken for blood pressure, heart disease, to thin the blood, or for prevention of stroke? If the answer to any of these questions is yes in a student 65 years of age or older, ask permission to partner with their physician so you can seek guidance in creating a safe and effective yoga practice. If you are ever uncertain as to whether or not a specific posture or practice is safe, avoid it. Observe the safety-first principle-when in doubt, do not do it. 


\section{Osteoporosis}

The word osteoporosis means porous bones and is a disorder of impaired bone strength due to a combination of low bone mass and poor bone quality, which results in skeletal fragility and increased fracture risk. ${ }^{26}$ In the United States, 10 million people have osteoporosis and 34 million more have low bone mass-or osteopenia-placing them at increased risk for further bone loss resulting in osteoporosis. ${ }^{27}$ While losing bone is a natural part of the aging process, osteoporosis is preventable or, at least, can be delayed. The disorder is caused by an imbalance between the natural processes of bone breakdown and bone formation, which occurs in women after menopause and in both men and women with aging. Certain characteristics put people at greater risk of osteoporosis, including gender-women after menopause are three times more likely to develop the disorder than men ${ }^{28}$ - small body size, and age. The longer you live, the greater your likelihood of developing osteoporosis. While not every older person gets the disease, the number increases from about $15 \%$ of women in their fifties to half of all women in their $80 \mathrm{ss}^{29}$ Due to the aging of the population, the prevalence of osteoporosis is expected to increase, so that, by 2020, 1 in 2 Americans over age 50 is expected to have or to be at risk of developing osteoporosis of the hip; even more will be at risk of developing osteoporosis at any site in the skeleton. ${ }^{30}$

The "gold standard" for diagnosis is a bone mineral density (BMD) measurement at the hip and spine, using dual-energy X-ray absorptiometry. The World Health Organization definition of osteoporosis is BMD of 2.5 standard deviations below that of an average young adult, and Tscore at or below $-2.5 .^{31}$ Osteopenia (low bone mass) is defined as a BMD between 1 and 2.5 standard deviations below this same mean, and $\mathrm{T}$ score of -1 to -2.5 . The United States Preventive Services Task Force recommends that BMD testing is appropriate for all women over age 65 and for women under age 65 who are postmenopausal and have risk factors for osteoporosis. Similarly, BMD testing is recommended for all men over age 70 and for men under age 70 if they have risk factors. Testing also is appropriate for younger people who have diseases or use medications that cause bone loss.

While it is recommended that people who are diagnosed with osteoporosis receive education about fracture prevention, it is our experience that few people diagnosed with osteoporosis have been told-or understand-how to reduce their risk of fracture. Indeed, we have encountered numerous seniors who are unsure whether or not they have osteoporosis-even if they are taking prescription medications specifically for this condition-and often confuse the condition with osteoarthritis or osteopenia. It is also critical to recognize that a significant number of people with this "silent disease" of osteoporosis are undiagnosed and unaware that they are at increased risk of fracture.

The most common bones that break as a result of osteoporosis are the hip, wrist, and verterbral bodies of the spine. Surprisingly, two thirds of vertebral fractures do not come to clinical attention, which means that people with osteoporosis may suffer this kind of fracture either without pain, or with pain that is not recognized as originating from a vertebral fracture. A previous fracture is the strongest risk factor for having another fracture, so asking students if they have had fractures-particularly minimally traumatic ones-since age 50 will help yoga teachers identify students who are at high risk of having a new fracture. In addition, yoga teachers can observe two characteristics that are strongly suggestive of previous vertebral fractures:

- Loss of two or more inches in height (compared to maximum adult height)

- Fixed kyphosis (a forward curve of the spine that cannot be corrected by cuing the student to stand or sit more erectly).

If a student presents with either or both of these factors, it would be prudent to assume that he or she has had vertebral fractures and modify the yoga practice accordingly.

While many yoga postures and practices can be extremely beneficial in maintaining or improving muscle strength, restoring function and relieving pain in this population, certain common yoga poses should be relatively contraindicated for people with actual or suspected osteoporosis as they have the potential for significant harm ${ }^{32}$ - something not typically recognized in the yoga community. Spinal flexion (forward bending) and rotation of the spine (twisting) can place large and compromising loads on the anterior vertebral bodies ${ }^{33}$ and are often implicated when a fracture of a vertebral body occurs. $^{34}$ Indeed, the National Osteoporosis Foundation warns that "many exercises and activities such as yoga, Pilates, tennis, and golf may need to be avoided or adjusted because they often involve twisting and bending motions." ${ }^{\prime 35}$ They recommend that people diagnosed with osteoporosis:

- Avoid bending forward from the waist

- Avoid twisting of the spine to a point of strain

- Avoid twisting the trunk and bending forward when doing activities such as coughing, sneezing, vacuuming, or lifting.

- Avoid sit-ups, abdominal crunches, or toe-touches.

These precautions are important to consider in adapting yoga postures appropriately, since it is critical to avoid teaching movements that can cause fractures. Another important factor to consider in modifying postures is the concept of a loaded spine, which refers to the amount of pressure on the spine and represents a combination of the weight of the head and upper body as well as the pull and tug of muscles and ligaments on the vertebral bodies. When the vertebral bodies are under high load, the addition of flexion or rotation movements significantly increases the risk of vertebral fracture.

Different body positions result in differing amounts of load on the spine. These loads are independent of the addition of positioning related to asana. Below is a list of positions and their relative load on the spine.

Activities with increasing amount of load: ${ }^{36}$

- Lying supine

- Erect standing

- Walking

- Sitting

- Standing, lifting a $20-\mathrm{kg}$ weight with back straight and knees bent

- Slouched sitting

- Standing, flexed forward from the waist

- Sitting, flexed forward and rotated while lifting $20 \mathrm{~kg}$. 
Taking into consideration the significant and inalterable risk presented by certain postures, as well as the actual physical abilities of most students who begin yoga for the first time in their $60 \mathrm{~s}$ or $70 \mathrm{~s}$, we have opted to take a conservative approach in the postures we suggest in the Therapeutic Yoga for Seniors teacher training. As a result, we have eliminated seated forward bends and end-range twists from our recommended repertoire of postures, substituting safer variations, such as supine knees-to-chest pose and gentle supine, sidelying, and standing twists. Due to the risk associated with high spine loads, we also advise against head or shoulder stands and extreme spine flexion in any position.

\section{Summary: \\ Balancing Risks and Rewards}

Teaching yoga to seniors presents both significant risks as well as extraordinary rewards. Older adults can be extremely receptive to the profound benefits offered on all levelsphysical, emotional, mental, and spiritual. Unlike younger practitioners, who can become distracted by the desire for a shapelier body, older adults typically have a ripeness for the experience of ease and union, which provides an amazing opportunity for yoga teachers.

Yet with the increased physical vulnerabilities present in an aging population, it is imperative for yoga instructors to be guardians of safety. This requires a solid understanding of common medical conditions and their associated risks, as well as an ability to use this knowledge as a foundation for creating a safe and effective yoga practice. Creating a truly safe environment may often require letting go of preconceived and commonly held notions of what a yoga practice entails in order to open to the joyful creativity and vast potential inherent in the experience of yoga.

It is a great honor and responsibility to meet our elders where they are, as they are, and to celebrate however they can join us in the practice of yoga-with great love and integrity.

\section{Disclosure Statement}

No competing financial interests exist.

\section{References}

1. Hatcher BJ. Center for Learning and Global Public Health. Global Aging: Impact of Human Resources for Health. Online document at: www.paho.org/english/dd/pin/HATCHER .pps Accessed June 24, 2010.

2. Day JC. National Population Projections. 2001. U.S. Census Bureau. Online document at: http://census.gov/population/ www/pop-profile/natproj.html Accessed June 24, 2010.

3. Wan H, Sengupta M, Velkoff VA, DeBarros KA. U.S. Census Bureau, Current Population Reports, P23-209, 65+ in the United States: 2005. Washington, DC: U.S. Government Printing Office, 2005.

4. Centers for Disease Control and Prevention and the Merck Company Foundation. The State of Aging and Health in America 2007: Executive Summary. Whitehouse Station, NJ: The Merck Foundation, 2007.

5. Centers for Disease Control and Prevention. Public health and aging: Trends in aging. United States and worldwide. Morbid Mortal Weekly Rep 2003;52:101-106.
6. Federal Interagency Forum on Aging-Related Statistics. Older Americans 2008: Key Indicators of Well-Being. Federal Interagency Forum on Aging-Related Statistics. Washington, DC: U.S. Government Printing Office, 2008.

7. Brault MW. Current Population Reports: Americans with Disabilities. 2005, Washington, DC: U.S. Department of Commerce, Economics and Statistics Administration, U.S. Census Bureau, 2008.

8. Table 98. In: National Center for Health Statistics. Health, United States, 2008: A Report of the Department of Health and Human Services, Hyattsville, MD: National Center for Health Statistics, 2009.

9. Merck Institute on Aging and Health. The State of Aging and Health in America, 2004. Online document at: http://cdc .gov/Aging/pdf/State_of_Aging_and_Health_in_America_ 2004.pdf Accessed June 24, 2010.

10. Centers for Disease Control and Prevention and The Merck Company Foundation. The State of Aging and Health in America 2007. Whitehouse Station, NJ: The Merck Company Foundation, 2007.

11. Centers for Disease Control and Prevention. Falls Among Older Adults. Online document at: //www.cdc.gov/Home andRecreationalSafety/Falls/adultfalls.html Accessed June 24, 2010.

12. Melton LJ III. How many women have osteoporosis now? J Bone Miner Res 1995;10:175-177.

13. U.S. Department of Health and Human Services. Bone Health and Osteoporosis: A Report of the Surgeon General. Rockville, MD: Office of the Surgeon General, U.S. Department of Health and Human Services, 2004.

14. National Center for Health Statistics. Health, United States, 2008: A Report of the Department of Health and Human Services. Hyattsville, MD: National Center for Health Statistics, 2009.

15. National Institute on Aging, Sleep and Aging. NIH Seniors Health. Online document at: http://nihseniorhealth.gov/ sleepandaging/aboutsleep/01.html Accessed June 24, 2010.

16. Mazzeo RS. Exercise and the Older Adult: American College of Sports Medicine, ACSM Current Comment, 2007. Online document at: www.acsm.org Accessed June 24, 2010.

17. U.S. Department of Health and Human Services. Physical Activity and Health: A Report of the Surgeon General, Atlanta, GA: U.S. Department of Health and Human Services, National Center for Chronic Disease Prevention and Health Promotion, Centers for Disease Control and Prevention, 1996.

18. Physical Activity Guidelines Advisory Committee. Physical Activity Guidelines Advisory Committee Report, 2008. Washington, DC: U.S. Department of Health and Human Services, 2008. Online document at: www.health.gov/ PAGuidelines/Report/pdf/CommitteeReport.pdf Accessed June 24, 2010.

19. Active Older Adults. In: Physical Activity Guidelines Advisory Committee. Physical Activity Guidelines Advisory Committee Report, 2008. Washington, DC: U.S. Department of Health and Human Services, 2008. Online document at: http://health.gov/paguidelines/guidelines/chapter5.aspx Accessed June 24, 2010.

20. Nelson ME, Rejeski WJ, Blair SN, et al. Physical activity and public health in older adults: Recommendation from the American College of Sports Medicine and the American Heart Association. Med Sci Sports Exerc 2007;39:1435-1445.

21. Coronary Artery Disease Fact Sheet. Medline Plus, National Library of Medicine. National Heart, Lung and Blood In- 
stitute. Online document at: http://nlm.nih.gov/medlineplus/ coronaryarterydisease.html\#cat1 Accessed June 24, 2010.

22. Know the Facts, Get the Stats. The American Heart Association. Online document at: http://americanheart.org/ downloadable/heart/116861545709855-1041\%20KnowThe FactsStats07_loRes.pdf Accessed June 24, 2010.

23. Rosamond W, Flegal K, Furie K, et al., for the American Heart Association Statistics Committee and Stroke Statistics Subcommittee. AHA Statistical Update: Heart Disease and Stroke Statistics-2008 Update. A Report From the American Heart Association Statistics Committee and Stroke Statistics Subcommittee. Circulation 2008;117:e25-c146. Online document at: http://circ.ahajournals.org/cgi/content/full/ 117/4/e25 Accessed June 24, 2010.

24. Vogel J, Krucoff M. Integrative Cardiology. New York: McGraw-Hill Medical, 2007.

25. Vogel J, Krucoff. ACC CAM Consensus Statement. J Am Coll Cardiol 2005;46:184-221.

26. NIH Consensus Development Panel on Osteoporosis Prevention. Osteoporosis prevention, diagnosis and therapy. JAMA 2001;285:785-795.

27. National Osteoporosis Foundation. America's Bone Health: The State of Osteoporosis and Low Bone Mass in Our Nation. Washington, DC: National Osteoporosis Foundation, 2002.

28. Genant HK, Cooper C, Poor G, et al. Interim Report and Recommendations of the World Health Organization Task-Force for Osteoporosis. Osteoporosis Int 1999;10: 259-264.

29. Praemer A, Furner S, Rice DP. Musculoskeletal Conditions in the United States. Rosemont, IL: American Academy of Orthopaedic Surgeons, 1999:182.
30. U.S. Department of Health and Human Services. Bone Health and Osteoporosis: A Report of the Surgeon General. Rockville, MD: Office of the Surgeon General, U.S. Department of Health and Human Services, 2004.

31. Kanis JA, Melton LJ III, Christiansen C, et al. The diagnosis of osteoporosis. J Bone Miner Res 1994;9:1137-1141.

32. Bouxsein ML, Myers ER, Haways WC. Biomechanics of agerelated fractures. In: Marcus R, Feldman D, Kelsey J, eds. Osteoporosis. New York: Academic Press, 1996:373-393.

33. Schultz AB, Andersson GBJ, Hadersperk K, et al. Analysis and measurement of lumbar trunk loads in tasks involving bends and twists. J Biomech 1982;15:669-675.

34. Melton LJ, Chao EYS, Iane J. Biomechanical aspects of fractures. In: Riggs BJ, Melton Lj, eds. Osteoporosis: Etiology, Diagnosis, and Management. New York: Raven Press, 1998;119-122.

35. Bone Basics, Moving Safely. The National Osteoporosis Foundation. Online document at: www.nof.org/osteoporosis/ Guidelines_for_Safe_Movement.pdf Accessed June 24, 2010.

36. Nachemson A. Towards a better understanding of low-back pain: A review of the mechanics of the lumbar disc. Rheum Rehabil 1975;14:129-143.

Address correspondence to: Carol Krucoff, E-RYT

Duke Integrative Medicine Duke University 3475 Erwin Road Durham, NC 27705

E-mail: ckrucoff@gmail.com 
